\title{
Evaluation of the common conditions associated with eosinophilia
}

\author{
CG TEO,${ }^{*}$ M SINGH,${ }^{*}$ WC TING $\dagger$ LC HO,${ }^{*}$ YW ONG,$\dagger$ LC SEET $\ddagger$ \\ From the * Department of Microbiology, National University of Singapore, the Department of Haematology, \\ Singapore General Hospital, and $\ddagger$ the Medical Services Headquarters, Singapore Armed Forces
}

SUMMARY In an eosinophilic population of 47 boys of the same age, a large proportion (92\%) were helminth infested or atopic, or both, compared with $36 \%$ of 36 controls. The methods used to detect these conditions were not costly or elaborate, except for the radioallergosorbent test, which was used to measure concentrations of circulating IgE antibodies to atopic allergens. It is suggested that an economical approach to detect helminthiasis and atopy in cases of eosinophilia is adopted using the methods employed here, with skin prick tests replacing the radioallergosorbent test.

Mild or moderate increases in blood eosinophil counts, detected from differential leucocyte counts, may be encountered during routine health screening as an isolated laboratory abnormality without an apparent association with disease or as an epiphenomenon during a diagnostic "work up" for an illness. As with other laboratory abnormalities arising from such situations, the clinician must judge the extent of diagnostic effort needed to evaluate the unexpected findings. ${ }^{1}$ Directing appropriate and cost effective investigations of isolated or incidental, mild to moderate eosinophilia requires knowledge of the various specific conditions associated with it. We have selected an eosinophilic population in Singapore that could allow a fuller and more specific characterisation of the common-that is, parasitic and allergic-causes of eosinophilia. From the results we discuss an approach, appropriate to both tropical and temperate regions, for initial evaluation of isolated or incidental eosinophilia.

\section{Patients, material, and methods}

We have reported elsewhere the haematological profiles of $99016^{1 / 2}$ year old boys undergoing mandatory medical examinations before military service in Singapore. ${ }^{2}$ The eosinophil counts, determined by the product of total leucocyte count (using the Coulter Counter S Plus II) and percentage of eosinophils in 200 leucocytes, were obtained from the same individuals. Serum samples through antecubital venepuncture were also obtained and were stored at $-20^{\circ} \mathrm{C}$. All blood samples were taken in the morning. Those with eosinophil counts greater than $0.4 \times$ $10^{9} / 1$ were recalled one and a half months later for a recount. Only individuals with second counts that exceeded $0.4 \times 10^{9} / 1$ were considered to have persistent eosinophilia and they formed the study population; there were $47(4.7 \%)$ of them. Of those who did not show eosinophilia at the first blood count, 60 were randomly selected for a recount after a similar interval; 36 had persistently normal eosinophil counts and they formed the non-eosinophilic control group.

At the time of the second blood count individuals in the two groups were asked for history of allergy, other illnesses, recent ingestion of drugs, and cigarette smoking. Clinical examination was done as directed by the history.

Stool samples were collected at the same time and were examined for intestinal helminths after concentration in formalin ether; for positive identification of hookworms and Strongyloides stercoralis, the stools were cultured to the third larval stage and then examined. A second stool sample was similarly examined one month later.

To test for filariasis, which is endemic in Singapore, an indirect immunofluorescence antibody assay was performed using sonicated microfilariae of Brugia malayi as antigens, according to the method of Singh et al. ${ }^{3}$ An indirect enzyme linked immunosorbent assay (ELISA) for toxocaral antibodies using Toxocara canis second stage larval secretory antigen was performed, using a method similar to that of de Savigny et al. ${ }^{4}$ Antigen coated 
polyvinyl microtitre plates and negative and positive control sera were kindly provided by Dr A Voller of the London School of Hygiene and Tropical Medicine; an additional positive control serum was provided by $\mathrm{Dr} R$ Berquist of Statens Bakteriologiska Laboratorium, Stockholm. No further search for evidence of other helminths was done.

To determine further the extent of atopy in the two groups the concentrations of circulating $\operatorname{IgE}$ antibodies specific to the following allergens were assayed by radioallergosorbent test (RAST) ${ }^{\text {s }}$ using Phadebas RAST Kits (Pharmacia Diagnostics): Dermatophagoides pteronyssinus, dog dander, cat epithelium, Aspergillus fumigatus, Cladosporium herbarum, egg, and pork. The choice of these allergens was guided by previous studies in Singapore of allergic conditions. ${ }^{6-9}$ The tests were performed according to the manufacturer's instructions, except that duplicate rather than single serum samples from each individual were assayed, as recommended elsewhere. ${ }^{10}$ The concentration of $\operatorname{IgE}$ specific to each allergen was classified in Phadebas RAST classes $0-4$, with class 3 or 4 being considered positive - that is, with high concentrations of allergen specific IgE.

In this study, a boy was considered atopic if his serum reacted positively to one or more RAST allergens, since he had then shown evidence of IgE related reactivity to exposure to common allergens found in the environment."

Total serum IgE concentrations were determined by the solid phase radioimmunoassay using a sandwich technique, where anti-IgE is coupled to paper disc (Phadebas PRIST Kits, Pharmacia Diagnostics); the tests were done as directed by the manufacturer.
Differences between groups in non-quantitative characteristics were assessed by the $\chi^{2}$ test. Differences in mean IgE concentrations were tested by Student's $t$ test after the values were log transformed to approximate a Gaussian distribution. ${ }^{12}$ Differences in eosinophil counts were compared nonparametrically using the Mann-Whitney $U$ test. ${ }^{13}$

\section{Results}

None of the boys in either group had clinical evidence of conditions associated with eosinophilia other than atopy or parasitism. Also none of them was currently ingesting drugs known to evoke eosinophilia.

Table 1 shows for both groups, the eosinophil counts, the number of current cigarette smokers, the number with helminthiasis or positive reactions to one or more allergens, or both, and the IgE concentrations. Thirty boys in the eosinophilic group compared with eight in the non-eosinophilic group had helminthiasis $(p=0.005)$. The distribution of infestations is shown in Table 2.

The sera of 20 boys in the eosinophilic group and only six in the non-eosinophilic group showed positive reactions to one or more allergens $(p=0.025)$. Except for one sample from the eosinophilic group which reacted to $D$ pteronyssinus and cat epithelium, all of the positive sera reacted only to $D$ pteronyssinus.

In the eosinophilic group there were 23 boys who had helminthiasis only, 13 who had positive reactions to one or more RAST allergens but who had no helminthiasis, and seven who had both; the mean eosinophil counts were $0.86,0.74$, and $0.61 \times 10^{9} / 1$ respectively. No significant differences were found

Table 1 Eosinophil counts, IgE values, number of individuals currently smoking cigarettes, and number with helminthiasis or positive reactions to one or more RAST allergens or both

\begin{tabular}{|c|c|c|c|c|}
\hline & $\begin{array}{l}\text { Mean and range of } \\
\text { eosinophil counts } \\
\left(\times 10^{\circ} / l\right)\end{array}$ & No currently smoking & $\begin{array}{l}\text { No with helminthiasis } \\
\text { or positive reactions to } \\
\text { one or more allergens or both }\end{array}$ & $\begin{array}{l}\text { Geometric mean of IgE } \\
\text { concentrations (kU/l) }\end{array}$ \\
\hline Eosinophilic group $(n=47)$ & $0.76(0.42-2 \cdot 14)$ & 14 & 43 & 835 \\
\hline $\begin{array}{l}\text { Non-eosinophilic group } \\
(\mathrm{n}=36) \\
\text { Significance of difference }\end{array}$ & $0.12(0-0 \cdot 38)$ & 11 & $\begin{array}{l}13 \\
p=0.005\end{array}$ & $\begin{array}{l}231 \\
\mathrm{p}<0.0005\end{array}$ \\
\hline
\end{tabular}

*Includes only the values obtained from the first blood count (see text).

NS = not significant.

Table 2 No of individuals with helminthiases as detected by faecal examinations and by serology

\begin{tabular}{lccccc}
\hline & $\begin{array}{l}\text { Helminthiases detected } \\
\text { by faecal examinations }\end{array}$ & Toxocariasis & Filariasis & $\begin{array}{l}\text { Toxocariasis and } \\
\text { helminthiases detected by } \\
\text { faecal examinations }\end{array}$ \\
\hline Eosinophilic group & 25 & 2 & 0 & 3 & 30 \\
Non-eosinophilic group & 7 & 0 & 1 & 0 & 8 \\
\hline
\end{tabular}


between any of these subgroups.

Total IgE concentrations of the three subgroups in the eosinophilic population were also compared. Geometric means of those with helminthiasis only, those with positive reactions to one or more allergens but not helminthiasis, and those who had both were 1170,685 , and $651 \mathrm{KU} / \mathrm{l}$ respectively. While the difference between the first and second groups was significant $(p<0 \cdot 0005)$, other differences were not.

\section{Discussion}

Our eosinophilic and non-eosinophilic groups were drawn from a population of adolescents in an attempt to obtain cases of parasitism and atopy only, which are the common conditions associated with eosinophilia in the general population. The likelihood of finding non-parasitic, non-atopic causes of eosinophilia, which occur more frequently in the older age groups (with the exception of Hodgkin's disease), was minimised in our adolescent population. Also, because of its homogeneous character, the need to adjust for possible age related differences in certain parameters-for example, eosinophil counts ${ }^{14}$ or IgE concentrations ${ }^{15}{ }^{16}$-was obviated.

Cigarette smoking has been reported to be associated with increased eosinophil counts ${ }^{16}{ }^{17}$ and was a potential confounding variable in this study. This possibility was excluded when no significant difference in the number of smokers between the two groups was found.

We identified 43 of $47(91.5 \%)$ eosinophilic individuals with helminthiasis or atopy compared with 13 of $36(36 \cdot 1 \%)$ in the non-eosinophilic group. The rest of the $8.5 \%$ in the eosinophilic group probably had rarer forms of allergy, parasitosis, or other eosinophilia associated conditions not detectable by the methods used by us. They could also be normal, particularly if the eosinophil counts were near the arbitrary cut off value of $0.4 \times 10^{9} / 1$, given the relatively imprecise method of counting eosinophils, ${ }^{18} 19$ although we have minimised this by defining eosinophilia only after two successive high counts.

The results of this study may be applied to form an approach to evaluate eosinophilia as an isolated or incidental laboratory abnormality. Searching for parasitism or atopy or both, depending on the geographical region of origin of the subject, is the obvious first step. In the clinically apparent cases clinical evaluation may provide a direction for deciding further confirmation. In clinically silent cases other clues may be sought; the eosinophil count may be considered since that in helminthiasis is higher than that in atopy, although in this study they were not significantly different. Total IgE concentration, which was higher in the helminth infested group than in the atopic groups, is probably not useful in routine evaluation because of its cost.

Specific detection of helminthiasis naturally starts with stool examination for helminth eggs. The extent to which a further search for helminthiasis should be made when stool examinations are negative depends on whether the specific infestations being sought are endemic in the region from which the subject originates. In our study, although we could identify most cases of helminthiasis in the eosinophilic group from stool examinations alone, several more with toxocariasis were detected by serology. Testing for toxocariasis in cases of eosinophilia should indeed be the next step after stool examinations since clinically inapparent toxocariasis has been recognised ${ }^{20}$ in endemic areas which include both tropical and temperate regions. ${ }^{21}$ The enzyme linked immunoassay used here is sensitive, specific, and inexpensive; its routine use is advocated but it may have to be done in a laboratory that does a large number of tests. ${ }^{4}$

Tests for evidence of atopy may be done concomitantly with the parasitic search, particularly when the subject is from the tropics since atopic conditions are not uncommon here even though helminthiasis may be endemic. ${ }^{22} 23$ In so doing, we detected $16.3 \%$ in the eosinophilic group with both helminthiasis and atopy. Tests such as RAST, which we used here, are expensive; in routine evaluation for atopy in cases of eosinophilia, skin prick tests may be used, which are cheaper and may be as effective. $^{2425}$ But some individuals with both helminthiasis and atopy may not react to skin tests. ${ }^{26}$

In any case, unlike evaluating an atopic patient with symptoms, the asymptomatic eosinophilic subject need only be tested with a few known common allergens since the goal here is merely to determine if he is atopic or not; a subject with a positive reaction to one common allergen could be considered atopic $^{11}$ and an association with eosinophilia is thus found. Furthermore, in regions with high humidity where house dust mites prevail, thereby acting as an ubiquitous source of atopic allergen, testing for reactivity to it alone may be sufficient to ascertain the atopic status, as we have found in this study.

The fall in eosinophilic count after treatment of helminthiasis establishes that there has been a helminthic cause of eosinophilia. Atopy, at best, can only be considered a condition associated with but not causing eosinophilia since it cannot be justifiably treated.

Hence, as an initial approach to evaluate cases of eosinophilia, particularly those with associated conditions not clinically apparent, we suggest: $(a)$ faecal examinations for helminth eggs, (b) further evalua- 
tion of other endemic helminthiasis not detectable by faecal assessment, (c) skin prick tests using a limited number of known common allergens.

Most publications on clinical aspects of eosinophilia, ${ }^{27}{ }^{28}$ while providing details on the causes of eosinophilia, do not discuss the approach to evaluate it as an incidental or isolated laboratory abnormality. Our approach suggested here is, within economical confines, comprehensive and judicious enough. Only when it yields negative results is there a need to use other more involved tests ${ }^{29}$ to search for the rarer causes.

We thank Dr A Voller for providing toxocaral antigen coated plates and control sera and Dr R Berquist for providing toxocara positive serum.

\section{References}

' Wilson JUG. Current trends and problems in health screening. $J$ Clin Pathol 1973;26:555-63.

${ }^{2}$ Teo CG, Seet LC, Ting WC, Ong YW. Anemia in male adolescents in Singapore. Pathology 1984; 16:141-5.

${ }^{3}$ Singh M, Kane GJ, Yap EH, Ho BC, Mak JW, Kang KL. Studies on human filariasis in Malaysia: immunodiagnosis using indirect immunofluorescence. Southeast Asian J Trop Med Pub Hlth 1979;10:486-97.

${ }^{4}$ de Savigny DH, Voller A, Woodruff AW. Toxocariasis: serological diagnosis by enzyme immunoassay. J Clin Pathol 1979;32:284-8.

${ }^{5}$ Wide L, Bennich H, Johansson SGO. Diagnosis of allergy by an in-vitro test for allergen antibodies. Lancet 1967;ii: 1105.

- Teoh PC, Tan WC, Oon CJ, Liu KF. Prick skin tests in bronchial asthma and their correlation with the specific serum IgE levels. Singapore Med J 1977; 18:228-31.

7 Tan WC, Teoh PC. An analysis of skin prick test reactions in asthmatics in Singapore. Ann Allergy 1979;43:44-6.

${ }^{8}$ Chee YC. Skin-prick tests for atopy in asthmatic adults in Singapore. ASEAN J Clin Sciences 1982;3:259-64.

${ }^{9}$ Lim TK, Chan TB, Tan WC, Teoh PC. The prevalence of skin sensitization to Aspergillus antigens among asthmatic patients in Singapore. Asian Pacific Journal of Allergy and Immunology 1983; 1:123-4.

${ }^{10}$ Evan R. Variability in the measurement of specific immunoglobulin E antibody by the RAST procedure. J Allergy Clin Immunol 1982;69:245-52.

" Pepys J. Atopy. In: Gell PGH, Coombs RRA, Lachmann PJ, eds. Clinical aspects of immunology. 3rd ed. Oxford: Blackwell, 1975:877-902.

12 Johansson SGO. Raised levels of a new immunoglobulin class (Ig ND) in asthma. Lancet 1967;ii:951-3.

${ }^{13}$ Siegel S. Non-parametric statistics for the behavioural sciences. Tokyo: Kogakusha-McGraw Hill, 1956:116-27.

${ }^{14}$ Burrows B, Hasan FU, Barbee RA, Halonen U, Lebowitz MD Epidemiologic observations on eosinophilia and its relation to respiratory disorders. Am Rev Resp Dis 1980;122:709-19.

is Berg T, Johansson SGO. Immunoglobulin levels during childhood, with special regard to IgE. Acta Paediat Scand 1969; 58: 513-24.

${ }^{16}$ Halonen M, Barbee RA, Lebowitz MD, Burrows B. An epidemiologic study of the interrelationships of total serum immunoglobulin E, allergy skin-test reactivity and eosinophilia. J Allergy Clin Immunol 1982;69:221-8.

${ }^{17}$ Schoen I, Pizer M. Eosinophilia apparently related to cigarette smoking. N Engl J Med 1964;270:1344-7.

${ }^{18}$ Rumke CL, Bezemer PD, Kuik DJ. Normal values and least significant differences for differential leukocyte counts. $J$ Chron Dis 1975;28:661-8.

${ }^{19}$ England JU, Bain BJ. Total and differential leucocyte count. Br J Haematol 1976;33:1-7.

${ }^{20}$ Bass JL, Mehta KA, Glickman LT, Eppes BM. Clinically inapparent toxocara infection in children. $N$ Engl $J$ Med 1983;308: 723-4.

21 Glickman LT, Schantz PM. Epidemiology and pathogenesis of zoonotic toxocariasis. Epidemiol Rev 1981;3:230-50.

22 Turner KJ. The conflicting role of parasitic infestations in modulating the prevalence of asthma. Papua New Guinea Med J 1978;21:86-104.

${ }^{23}$ Grove DI. What is the relationship between asthma and worms? Allergy 1982;37:139-48.

${ }^{24}$ Platts-Mills TAE. Type I or immediate hypersensitivity: Hay fever and asthma. In: Lachmann PJ, Peters DK, eds. Clinical aspects of immunology. 4th ed. Oxford: Blackwell, 1982:579-686.

${ }^{25}$ Thompson RA, Bird AG. How necessary are specific IgE antibody tests in allergy diagnosis? Lancet 1983;i:169-73.

${ }^{26}$ Lynch NR, Lopez R, Isturiz G, Tenias-Salazar E. Allergic reactivity and helminthic infection in Amerindians of the Amazon Basin. Int Arch Allergy Appl Immunol 1983;72:369-72.

${ }^{27}$ Beeson PB, Bass DA. The eosinophit. Philadelphia: Saunders, 1977.

28 Weller PF. Eosinophilia. J Allergy Clin Immunol 1984;73: 1-10.

${ }^{29}$ Spry CJF. Eosinophilia. The Practitioner 1982;226:79-88.

Requests for reprints to: Dr CG Teo, Department of Medical Microbiology. London School of Hygiene and Tropical Medicine, Keppel Street, London WC1E 7HT, England. 